\title{
Histiocitosis de células de Langerhans: seguimiento de 5 años y revisión sistemática de literatura.
}

Benanette Medina Ruiz, ${ }^{1}$
Lis Arocho,
${ }^{2}$
Lydia M López Del-Valle, ${ }^{3}$
Damaris Molina-Negrón. ${ }^{4}$

\section{Resumen}

La Histiocitosis de células de Langerhans (HCL), es una enfermedad rara, caracterizada por la proliferación clonal agresiva de células de Langerhans dendríticas de la médula ósea. La enfermedad crea lesiones osteolíticas en donde las manifestaciones orales usualmente están presentes. El objetivo de este reporte de caso es, presentar el seguimiento de cinco años de un caso diagnosticado en el 2014 y una revisión sistemática de literatura de las manifestaciones orales de HCL. Para la revisión sistemática, el argumento de búsqueda con palabras claves como HCL, histiocitosis $\mathrm{X}$ y manifestaciones orales, fueron conducidas en cinco bases de datos como PUBMED, LILACS, EBSCO, OVID y SCOPUS. Las manifestaciones orales más comunes son inflamación, enrojecimiento y pérdida de hueso en las áreas afectadas. Es importante mantener un seguimiento periódico en el consultorio dental de los casos de HCL en la población pediátrica. La HCL usualmente presenta manifestaciones orales que pueden ser un signo de diagnóstico temprano de esta condición, especialmente en la población pediátrica.

Palabras clave: Infante, Histiocitosis de células de Langerhans, periodontitis, manifestaciones bucales.

\footnotetext{
${ }^{1}$ Residente Programa Postdoctoral de Odontopediatría, Universidad de Puerto Rico, Escuela de Medicina Dental, San Juan, P.R

${ }^{2}$ Profesora Auxiliar, Programa Graduado de Cirugía Oral y Maxilofacial, Universidad de Puerto Rico, Escuela de Medicina Dental, San Juan, P.R.

${ }^{3}$ Profesora, Universidad de Puerto Rico, Escuela de Medicina Dental, San Juan, P.R.

${ }^{4}$ Profesora, Decana Auxiliar de Asuntos Académicos, Universidad de Puerto Rico, Escuela de Medicina Dental, San Juan, P.R.
} 


\section{Histiocitose de células de Langerhans: acompanhamento de 5 anos e revisão sistemática da literatura.}

\section{Resumo}

A histiocitose de células de Langerhans (HCL) é uma doença rara caracterizada pela proliferação clonal agressiva de células dendríticas de Langerhans da medula óssea. A doença cria lesões osteolíticas onde as manifestações orais geralmente estão presentes. $\mathrm{O}$ objetivo deste relato de caso é apresentar o seguimento de cinco anos de um caso diagnosticado em 2014 e uma revisão sistemática da literatura sobre as manifestações orais da HCL. Para a revisão sistemática, a busca de argumento com palavras-chave como LCH, histiocytosis $X$ e oral manifestations, foi realizada em cinco bases de dados como PUBMED, LILACS, EBSCO, OVID e SCOPUS. As manifestações orais mais comuns são inflamação, vermelhidão e perda óssea nas áreas afetadas. É importante monitorar regularmente os casos de HCLna população pediátrica no consultório odontológico. A HCL geralmente apresenta manifestações orais que podem ser um sinal diagnóstico precoce dessa condição, principalmente na população pediátrica.

Palavras-chave: Lactente, Histiocitose de células de Langerhans, periodontite, manifestações orais.

Case report

\section{Langerhans cell histiocytosis: 5-year follow-up and systematic literature review.}

\begin{abstract}
Langerhans cell histiocytosis (LCH) is a rare disease characterized by aggressive clonal proliferation of dendritic Langerhans cells from the bone marrow. The disease creates osteolytic lesions where oral manifestations are usually present. The objective of this case report is to present the five-year follow-up of a case diagnosed in 2014 and a systematic review of the literature on the oral manifestations of $\mathrm{LCH}$. For the systematic review, the search argument with keywords such as LCH, histiocytosis $\mathrm{X}$ and oral manifestations, were conducted
\end{abstract}

in five databases such as PUBMED, LILACS, EBSCO, OVID and SCOPUS. The most common oral manifestations are inflammation, redness, and bone loss in the affected areas. It is important to regularly monitor $\mathrm{LCH}$ cases in the pediatric population in the dental office. LCH usually presents oral manifestations that can be an early diagnostic sign of this condition, especially in the pediatric population.

Keywords: Infant, Langerhans cell histiocytosis, periodontitis, oral manifestations. 


\section{Introducción}

La Histiocitosis de Células de Langerhans (HCL) es una enfermedad rara caracterizada por la proliferación clonal de células dendríticas de Langerhans con comportamiento agresivo. ${ }^{1,2}$ La HCL tiene una predilección por los hombres sobre las mujeres en una proporción de 2:1 y afecta predominantemente a 1 de cada 200,000 niños por año, con una incidencia máxima de 1 a 3 años, aunque puede desarrollarse a cualquier edad. ${ }^{1}$ Se caracteriza por la proliferación anormal de células Langerhans derivadas de la medula ósea. Su diagnóstico definitivo es establecido a través de un examen histológico y el tratamiento, usualmente incluye intervención quirúrgica, quimioterapia, radiación y corticoterapia. Su compromiso oral puede ser visto antes de las otras manifestaciones sistémicas o imitar trastornos de desórdenes infecciosos o inflamatorios. Debido a que las manifestaciones orales frecuentemente se exhiben en la población pediátrica es responsabilidad de los proveedores de salud oral reconocer los signos y síntomas clínico- patológicos, ya que, pueden cumplir un rol crítico y esencial en el diagnóstico de esta rara enfermedad. ${ }^{1}$

\section{Reporte de caso}

En el 2014, un dentista privado refirió a un paciente masculino de 3 años a la clínica de la Residencia de Odontopediatría de la Escuela de Medicina Dental de la Universidad de Puerto Rico, para evaluar una posible enfermedad periodontal en los segundos molares inferiores primarios1. El examen intraoral reveló una inflamación en la gingiva de los lados izquierdo y derecho, a nivel de los segundos molares inferiores primarios, obliterando el ángulo mandibular (Figura 1). Otros tejidos orales aparecieron dentro de los limites normales. En esa primera visita, luego del examen clínico, se obtuvo una radiografía panorámica la cual reveló una perdida ósea bilateral en los segundos molares primario derecho e

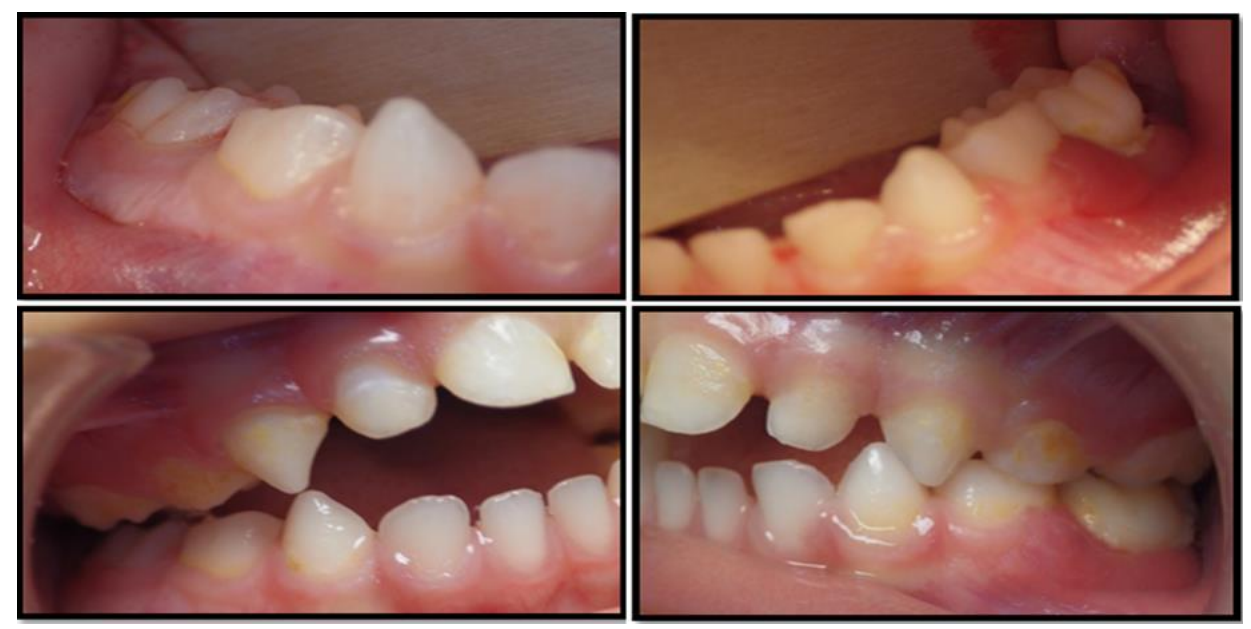

Figura 1. Fotografías intraorales. Las imágenes intraorales muestran encía enrojecida e inflamada alrededor del segundo molar primario mandibular derecho. Inflamación localizada y apariencia hemorrágica de la encía en la superficie facial de los molares primarios mandibulares izquierdos y la retención de placa generalizada también se nota en la mayoría de los dientes del paciente. 
izquierdo mandibular. La lesión del lado izquierdo mostraba un patrón radiolúcido extenso de márgenes irregulares desde el segundo molar primario hacia el folículo del primer molar permanente, desplazándolo posteriormente y creando una apariencia de dientes flotantes. ${ }^{1}$ El paciente recibió intervención quirúrgica con biopsia excisional y curetaje de las áreas afectadas con extracción de los segundos molares mandibulares primarios y el folículo del primer molar mandibular permanente izquierdo. Los especímenes obtenidos tanto del lado derecho como izquierdo mandibular fueron consistentes con Histiocitosis de Células de Langerhans. Posterior a este diagnóstico, el paciente fue referido al servicio de hematología/oncología para evaluación y tratamiento. Una tomografía computarizada fue ordenada la cual reveló que también había lesiones menores en el hígado y el área abdominal. El paciente fue tratado posteriormente con quimioterapia. Durante 3 años, el paciente continuó un protocolo riguroso de seguimientos dentales cada 3 meses con un dentista pediátrico y cada 6 meses con una cirujana maxilofacial. En el 2017, el seguimiento reveló en la radiografía panorámica y radiografía de mordida, una radio lucidez periapical del primer molar primario izquierdo envolviendo el primer premolar permanente. Debido al historial previo se tomó la decisión de realizar una segunda intervención en sala de operaciones donde se extrajeron el primer molar primario izquierdo y el folículo del primer premolar permanente izquierdo. El resultado de esa biopsia reveló un folículo dental agrandado y células inflamatorias sin evidencia de recurrencia de la lesión previa. En seguimiento, el paciente ha presentado exámenes clínicos y radiográficos periódicos sin evidencia de lesiones recurrentes. En el último seguimiento en el 2019, no reveló nuevas lesiones $y$ el paciente se encontraba asintomático. La Figura 2, resume la toma de radiografías panorámicas durante el periodo de 2014 a 2019.



Radiografía panorámica (2014). Paciente de 3 años, con lesión radiolúcida extensa del cuerpo mandibular izquierdo envolviendo el segundo molar primario izquierdo y el folículo del primer molar permanente izquierdo con desplazamiento del mismo.

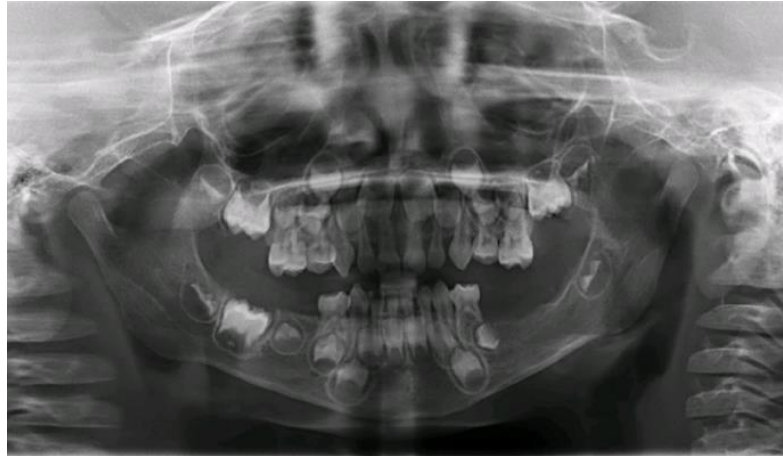

Radiografía panorámica (2015). Radiografía de seguimiento a los 3 meses postquirúrgicos mostrando un sanado óseo apropiado con continuidad mandibular sin evidencia de lesiones recurrentes.

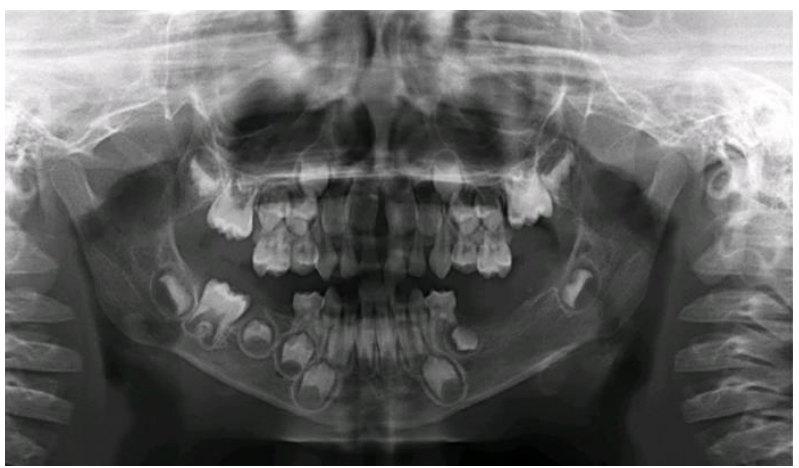

Radiografía panorámica (2016). Radiografía de seguimiento con estabilidad y continuidad ósea del cuerpo mandibular izquierdo sin evidencia de recurrencia de lesiones

Figura 2: Serie de radiografías. 


\section{Revisión de literatura}

Para completar este reporte de caso, se realizó una revisión de la literatura para analizar las diferentes manifestaciones orales, tratamiento y seguimiento para pacientes pediátricos con Histiocitosis de Células de Langerhans. La pregunta de investigación fue: ¿Cuáles son las manifestaciones orales más frecuentes para los pacientes de la población pediátrica con la enfermedad de Histiocitosis de Células de Langerhans?

\section{Materiales y métodos}

Para esta revisión de literatura, se utilizaron los criterios de declaración PRISMA y las pautas de CARE para analizar los informes de casos. Se realizó una búsqueda en línea de estudios y reportes de casos publicados en los años 2010 al 2020, incluyendo las siguientes bases de datos: PUBMED, EBSCO, OVID, PROQUEST, DIALNET Y SCOPUS utilizando las palabras claves de HCL, histiocitosis $\mathrm{X}$ y manifestaciones orales. Usando estas palabras claves se obtuvo el siguiente argumento de búsqueda y se aplicó a las bases de datos mencionadas.

Histiocitosis de Células de Langerhans \& (manifestación oral* $\mathrm{O}$ manifestación peri-oral $\left.{ }^{*}\right)$

Se aplicaron también los filtros (CRITERIOS DE INCLUSION) de: artículos basados en niños y adolescentes (edad 0 a 18 años) y reportes de caso y últimos 10 años

En la revisión de la literatura, un bibliotecario participó en la realización de las cadenas o argumentos de búsquedas. Las variables de resultado primarias consistieron en lesiones orales de pacientes con la enfermedad de Histiocitosis de Células de Langerhans. Se consideró en la inclusión de esta revisión, cualquier artículo relevante publicado en inglés o español de reporte de casos en pacientes de 18 años o menos, y que presentara las manifestaciones orales. Los informes de casos incluidos en esta revisión de literatura cumplieron con los criterios de la lista de verificación de CARE. La figura 3 presenta el flujograma PRISMA.

\section{Resultados}

En los resultados de la revisión de literatura se encontraron inicialmente 29 artículos que eran elegibles posiblemente. Después de remover los duplicados $(\mathrm{n}=1)$ quedaron 28 estudios de reportes de casos y series de casos que se investigaron de texto completo. De la base de datos de PUB MED se encontraron 7 artículos de los cuales fueron incluidos 2 casos (5 artículos no se incluyeron: 3 por no estar relacionados con la condición, 1 por inclusión de adultos y otro por estar en otro idioma diferente al inglés o español); en la base de Pro Quest se encontró solo 1 reporte de caso pero estaba duplicado, en la base de datos de Scopus se encontraron 13 artículos de los cuales se incluyeron 6 reportes de caso pero no se incluyeron 7 : 5 por no estar relacionados, 1 por estar en idioma diferente al inglés o español y 1 por ser de adultos y en la base de ESBCOST y OVID se encontraron 4 artículos y se incluyeron 1 reporte de caso ( 2 no estaban relacionados y 1 era un resumen y no tenía texto completo asociado. Se evaluaron los artículos con los criterios de inclusión y quedaron 13 artículos para incluir en la 
revisión bibliográfica (12 reportes de caso y 1 serie de casos).

\section{Discusión}

Los artículos seleccionados para esta revisión de literatura se resumen en la Tabla 1. Fueron 13 artículos de los cuales 12 fueron reportes de caso y 1 serie de casos (10 casos presentando un resumen retrospectivo).

En resumen, las manifestaciones más comunes reportadas fueron; inflamación y enrojecimiento de las encías o gingiva y pérdida de hueso en las áreas afectadas mayormente maxila y mandíbula, ulceraciones de la mucosa, movilidad de los dientes afectados, sangramiento de las encías o gingiva y problemas periodontales. De los artículos incluidos en esta revisión de literatura: 3 reportaron ulceraciones de la mucosa, 4 movilidad en dientes afectados, 1 necrosis de la gingiva, 5 inflamación gingival, 4 sangramiento de las encías, 1 problemas periodontales y 2 afección del paladar. De los 13 artículos incluidos en esta revisión 9 reportaron lesiones osteolíticas en la mandíbula o en área craneofacial. El artículo de Gómez et al (2013) que evaluó retrospectivamente una serie de 10 casos pediátricos de HLC reporto en su totalidad lesiones osteolíticas en área craneofacial. Con respecto a otras manifestaciones sistémicas se encontró en esta revisión que mayormente las afecciones son en piel, hígado, bazo, sistema hematopoyético y SNC además de un caso de diabetes insipidus. Las lesiones en piel son mayormente expresadas en forma de dermatitis. Las afecciones de los órganos son mayormente inflamatorias. El tratamiento seguido en todos los casos presentados es la quimioterapia combinada con cirugía y tratamiento con corticoesteroides.

En resumen, la histiocitosis de células de Langerhans (HCL) es una enfermedad poco frecuente, cuya incidencia se calcula en alrededor de un caso por 200.000 niños por año. Es más frecuente en los primeros años de vida, así como en el sexo masculino, con una proporción hombre: mujer de 2:1; cómo se puede ver en esta revisión de literatura. Las manifestaciones orales de HCL es una de las primeras manifestaciones de esta enfermedad y puede ser el primer y único signo de HCL, dándole al odontopediatra y al dentista general un importante rol en el diagnóstico temprano de la enfermedad previniendo así un desenlace fatal en la población pediátrica. También las lesiones orales pueden ser un signo temprano de la recurrencia o reactivación de la enfermedad en otros sistemas del cuerpo. Las lesiones orales como podemos ver en los reportes de casos de la revisión de literatura pueden ser múltiples o solitarias y estar caracterizadas por lesiones irregulares de superficie que causan ulceraciones en la mucosa y envolvimiento del hueso adyacente. Las lesiones gingivales son frecuentes causando recesión $\mathrm{y}$ sangramiento asociado $\mathrm{y}$ pérdida de inserción y movilidad de los dientes asociados. La mayoría de los pacientes de HCL están entre los 2 a los 10 años cuando se presenta con más frecuencia la condición. Las lesiones óseas solitarias se ven más frecuente entre los pacientes entre 5 y 15 años de edad; mientras aquellos con HCL envolviendo múltiples sistemas se presenta en pacientes menores de 5 años de edad. No hay un tratamiento estandarizado para el manejo de HCL. El tratamiento puede variar 


\section{Tabla 1. Resumen de revisión de literatura de los reportes de casos de Langerhan cell hystiocitosis (2010-2020)}

\begin{tabular}{|c|c|c|c|c|c|}
\hline Autor y Revista & Caso / Paciente & Manifestaciones orales & $\begin{array}{l}\text { Manifestaciones } \\
\text { sistémicas }\end{array}$ & $\begin{array}{l}\text { Seguimiento } \\
\text { del caso }\end{array}$ & Tratamiento \\
\hline $\begin{array}{l}\text { Erdem et al, Oral Health Prev } \\
\text { Dent 2013; } 11 \text { (1): 57-9 }\end{array}$ & Niño de 2 años & $\begin{array}{l}\text { Encías sangrantes Pérdida } \\
\text { de hueso Bolsillos } \\
\text { periodontales profundos }\end{array}$ & $\begin{array}{l}\text { Erupción } \\
\text { cutánea parecida } \\
\text { a dermatitis } \\
\text { seborreica }\end{array}$ & $\begin{array}{l}\text { No } \\
\text { reportado }\end{array}$ & Quimioterapia \\
\hline $\begin{array}{l}\text { Eduardo Costa Studart Soares et } \\
\text { al; J Clin Pediatr Dent Summer } \\
\text { 2012; 36(4): 377-81 }\end{array}$ & Paciente joven & $\begin{array}{l}\text { Lesiones en hueso en el } \\
\text { ramo mandibular }\end{array}$ & $\begin{array}{l}\text { Diabetes } \\
\text { insipidus }\end{array}$ & $\begin{array}{l}\text { No } \\
\text { reportado }\end{array}$ & Quimioterapia \\
\hline $\begin{array}{l}\text { Pipa Vallejo, A et al; Avances en } \\
\text { Odontoestomatologia } 2016 \text { Vol. } \\
32 \text { No. 4; } 187-193\end{array}$ & $\begin{array}{l}\text { Niño de } 14 \\
\text { meses }\end{array}$ & Gingivitis localizada & $\begin{array}{l}\text { Lesiones } \\
\text { cutáneas } \\
\text { descamatosas }\end{array}$ & $\begin{array}{l}\text { No } \\
\text { reportado }\end{array}$ & No reportado \\
\hline $\begin{array}{l}\text { Gomez AM et al; Rev CES Med } \\
\text { 2013; } 27 \text { (2): 177-184 }\end{array}$ & $\begin{array}{l}\text { Serie de } 10 \\
\text { casos } \\
\text { estudio } \\
\text { retrospectivo } \\
\text { de casos }\end{array}$ & $\begin{array}{l}\text { Lesiones en hueso en área } \\
\text { craneofacial }\end{array}$ & $\begin{array}{l}\text { Lesiones } \\
\text { en hueso, } \\
\text { SNC, hígado, } \\
\text { bazo, sistema } \\
\text { hematopoyético }\end{array}$ & $\begin{array}{l}\text { No } \\
\text { reportado }\end{array}$ & $\begin{array}{l}\text { Quimioterapia } \\
\text { Cirugía }\end{array}$ \\
\hline $\begin{array}{l}\text { Loreto Zyrpel M, et al; Rev } \\
\text { Española de Cirugía Oral y } \\
\text { Maxilofacial. } 2011 \text { Vol 33, No. } \\
\text { 3: 114-119 }\end{array}$ & Niño de 3 años & Lesión en hueso malar & No reportado & 18 meses & $\begin{array}{l}\text { Cortico- } \\
\text { esteroides } \\
\text { Curetaje lesión }\end{array}$ \\
\hline $\begin{array}{l}\text { Efrian Ramos Gutierrez et al; } \\
\text { Journal of Clinical and Exp } \\
\text { Dentistry, } 2016 \text { Vol. 8, No. 1: } \\
\text { 102-108 }\end{array}$ & Niña de 2 años & $\begin{array}{l}\text { Sangramiento de las encías } \\
\text { Dolor dental } \\
\text { Lesion en hueso maxilar }\end{array}$ & $\begin{array}{l}\text { Eritema de la } \\
\text { piel } \\
\text { Otitis media } \\
\text { Lesiones en } \\
\text { hígado, bazo y } \\
\text { médula ósea } \\
\end{array}$ & $\begin{array}{l}\text { No } \\
\text { reportado }\end{array}$ & $\begin{array}{l}\text { Quimioterapia } \\
\text { Cirugía }\end{array}$ \\
\hline $\begin{array}{l}\text { Hammouri Eman Hussein et al; } \\
\text { Clinical Case Reports; Bognor } \\
\text { Regis Vol. } 8 \text { Iss } 32020 \text { Marzo; } \\
545-549\end{array}$ & Niño de 2 años & $\begin{array}{l}\text { Ulceraciones orales } \\
\text { Sangramiento de la gingiva } \\
\text { Halitosis } \\
\text { Necrosis de la gingiva } \\
\text { Dientes movibles o sueltos } \\
\text { Lesiones en hueso } \\
\text { maxilar y mandibular } \\
\text { con componente de tejido } \\
\text { blando }\end{array}$ & No reportadas & $\begin{array}{l}\text { No } \\
\text { reportado }\end{array}$ & $\begin{array}{l}\text { Quimioterapia } \\
\text { Cirugía }\end{array}$ \\
\hline $\begin{array}{l}\text { Tenorio JDR et al, } 2020 \text { Journal } \\
\text { of Oral and Maxilofacial } \\
\text { Surgery Med and Pathology; } 32 \\
(1): 72-75\end{array}$ & $\begin{array}{l}\text { Niño de } 12 \\
\text { años }\end{array}$ & $\begin{array}{l}\text { Lesiones orales } \\
\text { Movilidad severa de los } \\
\text { dientes } \\
\text { Pérdida ósea severa en el } \\
\text { área posterior de molares y } \\
\text { premolares mandibulares }\end{array}$ & $\begin{array}{l}\text { Lesiones } \\
\text { cutáneas en piel }\end{array}$ & $\begin{array}{l}\text { No } \\
\text { reportado }\end{array}$ & $\begin{array}{l}\text { Quimioterapia } \\
\text { Cirugía }\end{array}$ \\
\hline $\begin{array}{l}\text { De Camargo Moraes P et al; Ped } \\
\text { Dental Journal; Vol. 29, Iss } 3 \\
\text { Dec 2019: 152-156 }\end{array}$ & Niña de 2 años & $\begin{array}{l}\text { Lesiones óseas } \\
\text { mandibulares } \\
\text { Nódulo enrojecido en } \\
\text { mandíbula } \\
\text { Inflamación de la gingiva } \\
\text { Sangramiento y movilidad } \\
\text { de dientes }\end{array}$ & Ninguno & 3 años & Cirugía \\
\hline $\begin{array}{l}\text { Routray S, et al; } 2019 \text { BMJ Case } \\
\text { Reports; } 12 \text { (7); art no. e } 229483\end{array}$ & Niño de 6 años & $\begin{array}{l}\text { Ulceraciones de la mucosa } \\
\text { oral } \\
\text { Inflamación del paladar } \\
\text { Pérdida ósea en área de los } \\
\text { maxilares }\end{array}$ & $\begin{array}{l}\text { Lesiones en la } \\
\text { dermis }\end{array}$ & $\begin{array}{l}\text { No } \\
\text { reportado }\end{array}$ & Quimioterapia \\
\hline $\begin{array}{l}\text { Halfarum E et al; Jouranl of } \\
\text { Dentistry for Children; Vol } 85 \\
\text { Iss } 2 \text { Mar-Agosto 2018: 75-78 }\end{array}$ & $\begin{array}{l}\text { Nino de } 5 \\
\text { meses de edad }\end{array}$ & Inflamación gingival & No reportada & 36 meses & $\begin{array}{l}\text { Quimioterapia } \\
\text { Cirugía }\end{array}$ \\
\hline $\begin{array}{l}\text { Hemmati S et al; Jouranl of } \\
\text { Mazendara Univ of MS Vol 26, } \\
\text { Iss 138, 2016: 209-214 }\end{array}$ & $\begin{array}{l}\text { Niño de } 2 \text { años } \\
\text { y medio }\end{array}$ & $\begin{array}{l}\text { Ulceraciones de la mucosa } \\
\text { Necrosis gingival } \\
\text { Movilidad de dientes } \\
\text { Radiolucencias en área } \\
\text { maxilar y mandibular }\end{array}$ & No reportada & 1 año & Quimioterapia \\
\hline
\end{tabular}


considerablemente por la naturaleza heterogénea de la condición que puede envolver múltiples órganos y sistemas. Por eso como vemos en la revisión de literatura, para lesiones solitarias, el curetaje local se usa más frecuentemente combinado con inyecciones de corticoesteroides; para las lesiones diseminadas, la quimioterapia y cirugía es lo que se recomienda. El trabajo en equipo con los profesionales médicos y el odontopediatra o dentista es importante; al igual que el continuo seguimiento de los casos de población pediátrica a través del tiempo.

\section{Conclusión}

Las manifestaciones orales de Langerhans en los artículos de la revisión de literatura y en el reporte de caso fueron inflamación, enrojecimiento y pérdida de hueso en áreas afectadas. Debido a la tasa de recurrencia de la enfermedad, recalcamos la importancia de los seguimientos en los pacientes que padezcan de esta condición. El diagnóstico temprano por los dentistas es de suma importancia, si se identifican estos hallazgos orales a una temprana edad, se puede comenzar tratamiento con tiempo y considerablemente disminuir la mortalidad y morbididad.

\section{Reconocimiento}

Queremos agradecer los esfuerzos colectivos de la facultad, residentes y personal del Programa Posdoctoral en Odontopediatría de la Escuela de Medicina
Dental de la Universidad de Puerto Rico, Recinto de Ciencias Médicas y del profesor Pedro Antonio Del Valle López, Bibliotecario III de la Universidad de Puerto Rico, Recinto de Ciencias Médicas por su colaboración en la búsqueda de datos en este artículo.

Conforme a los Estándares de Ética:

Fondos: Este estudio no tiene fondos.

Conflicto de Interés: Todos los autores de este estudio declaran ningún conflicto de interés. Ningún tipo de fondos o manutención financiera fueron recibidos por ningún autor para este estudio.

Aprobación ética: Ningún tipo de animal fue utilizado para este estudio.

(En caso de participación de humanos) Aprobación ética: Todos los procedimientos hechos en este estudio donde humanos participaron fueron hechos de acuerdo con los estándares de ética del comité institucional/nacional de investigación y con la declaración de Helsinki de 1964 y sus enmiendas posteriores o con otros estándares de ética comparables.

Consentimiento firmado por los padres/ tutores legales del paciente, anexo se envía información suplementaria.

(En caso de participación de humanos) Consentimiento Informado: Consentimiento informado obtenido de todos los individuos participantes en este estudio. 


\section{Referencias bibliográficas}

1. Da Fonseca R, López Del-Valle L, Arocho L, et al. Histiocitosis de Células de Langerhans. Rev Odotopediatr Latinoam. 2017; 7(2):144-150.

2. Halperson E, Weintraub M. Oral Langerhans Cell Histiocytosis in an Infant. Journal of Dentistry for Children. 2018; 85(2):75-78.

3. Erdem AP, Kasimoglu Y, Sepet E , Gencay K, Sahin S, Dervisoglu S. Oral manifestations may be the first sign of Langerhans cell histiocytosis. Oral Health Prev Dent. 2013; 11(1):57-9.

4. Costa Studart Soares E, Pinto Quidute AR, Gurgel Costa FW, Costa Gurgel MH, Negreiros Nunes Alves AP, Roriz Fonteles CS. Monostotic Langerhans' cell histiocytosis in a child with central diabetes insipidus J Clin Pediatr Dent. Summer 2012; 36(4):377-81.

5. González, I, Pipa Muñiz, M., González García, JC, de Vicente Rodríguez. Histiocitosis de células de Langerhans con implicación oral: a propósito de un caso. Avances en odontoestomatología, 2016; 32(4):187-193.

6. Gómez Vásquez, AM, Lotero V, Martínez PS, Medina D, Ramírez O. Histiocitosis de células de Langerhans en niños: descripción de 10 casos. Revista CES Medicina. 2013;27(2):177-184.

7. Castellón Zirpel ML, Fuenzalida Kakarieka C, Barrios Tapia JI, Uribe Fenner F. Histiocitosis de células de Langerhans localizada en hueso malar: presentación de un caso. Revista española de cirugía oral y maxilofacial: Publicación Oficial de la Sociedad Española de Cirugía Oral y Maxilofacial. 2011;33 (3):114119.

8. Ramos-Gutierrez E, Alejo-Gonzalez F, Ruiz Rodríguez S, Garrocho Rangel A, Pozos Guillén AdJ. Langerhans cell histiocytosis: current concepts in dentistry and case report. Journal of Clinical and Exp Dentistry. 2016; 8(1): 102-108

9. Hammouri EH, Sweidan HA, AShokaibi O, Al Omari L.Langerhans cell histiocytosis: A case report with oral manifestations and the role of pediatric dentists in the diagnosis. Clinical Case Reports. 2020; 8(3):545-549.

10. Tenório JDR, Esteves CV, Heguedusch D, de Sousa SCOM, Lemos-Júnior CA Oral and cutaneous manifestations of langerhans cell histiocytosis: report of two cases. Journal of Oral and Maxillofacial Surgery, Medicine, and Pathology. 2020; 32 (1):72-75.

11. de Camargo Moraes P, Montalli VAM, Tincani AJ, de Mendonça RMH, Alvarenga CA, Junqueira JLC, Oliveira LB. Langerhans cell histiocytosis: A case report in a 2-year old child. Pediatric Dental Journal. 2019; 29(3):152-156.

12. Routray S, Adhya AK, John J, Dikhit P. Revealing a rare inflammatory oral manifestation in a 6-year-old child. BMJ Case Reports. 2019;12(7):e229483.

13. Hemmati S, Nahvi A. Langerhans cell histiocytosis with primary oral manifestations: A case report. Journal of Mazandaran University of Medical Sciences. 2016; 26 (138):209-214.

Recibido: 25/07/2020

Aceptado: 08/11/2020

Correspondencia: Damaris Molina-Negrón, correo: damaris.molina@upr.edu 